\title{
THE GROWTH AND DOPING OF AL(AS)SB BY METAL-ORGANIC CHEMICAL VAPOR DEPOSITION
}

R. M. Biefeld, A. A. Allerman, and S. R. Kurtz

Sandia National Laboratory, Albuquerque, New Mexico, 87185, USA

ABSTRACT

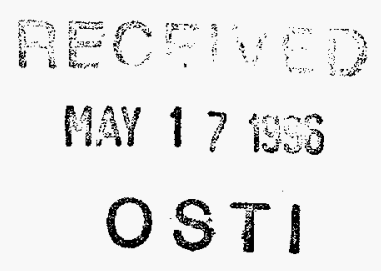

$\mathrm{AlSb}$ and $\mathrm{AlAs}_{\mathrm{x}} \mathrm{Sb}_{1-\mathrm{x}}$ epitaxial films grown by metal-organic chemical vapor deposition were successfully doped $\mathrm{p}$ - or $\mathrm{n}$-type using diethylzinc or tetraethyltin, respectively. AlSb films were grown at $500^{\circ} \mathrm{C}$ and 76 torr using trimethylamine or ethyldimethylamine alane and triethylantimony. We examined the growth of AlAsSb using temperatures of 500 to $600^{\circ} \mathrm{C}$, pressures of 65 to 630 torr, V/III ratios of 1-17, and growth rates of 0.3 to $2.7 \mu \mathrm{m} /$ hour in a horizontal quartz reactor. SIMS showed $C$ and $O$ levels below $2 \times 10^{18} \mathrm{~cm}^{-3}$ and $6 \times 10^{18} \mathrm{~cm}^{-3}$ respectively for undoped AISb. Similar levels of $O$ were found in $A l A s_{0.16} S b_{0.84}$ films but $C$ levels were an order of magnitude less in undoped and Sn-doped $\mathrm{AlAs}_{0.16} \mathrm{Sb}_{0.84}$ films. Hall measurements of $\mathrm{AlAs}_{0.16} \mathrm{Sb}_{0.84}$ showed hole concentrations between $1 \times 10^{17} \mathrm{~cm}^{-3}$ to $5 \times 10^{18}$ $\mathrm{cm}^{-3}$ for $\mathrm{Zn}$-doped material and electron concentrations in the low to mid $10^{18} \mathrm{~cm}^{-3}$ for $\mathrm{Sn}$ doped material. We have grown pseudomorphic InAs/InAsSb quantum well active regions on AlAsSb cladding layers. Photoluminescence of these layers has been observed up to $300 \mathrm{~K}$.

\section{INTRODUCTION}

$\mathrm{AlSb}$ and $\mathrm{AlAs}_{\mathrm{x}} \mathrm{Sb}_{1-\mathrm{x}}$ are of interest for their potential application in a variety of optoelectronic devices such as infrared detectors, resonant tunneling diodes, and laser diodes. ${ }^{1-}$ ${ }^{4}$ We are exploring the synthesis of these materials by metal-organic chemical vapor deposition (MOCVD) for their use as optical confinement materials in 2-6 $\mu \mathrm{m}$, mid-infrared optoelectronic and heterojunction devices. Emitters in this wavelength range have potential uses as chemical monitors and in infrared countermeasures..$^{1-4}$ Although devices using $\mathrm{AlAs}_{\mathrm{x}} \mathrm{Sb}_{1-\mathrm{x}}$ have been successfully prepared by molecular beam expitaxy, ${ }^{2,3}$ there have been no reports to date of their successful use in devices when prepared by metal-organic chemical vapor deposition (MOCVD). We are aware of two previous reports of the successful growth of $\mathrm{AlAs}_{\mathrm{x}} \mathrm{Sb}_{1-\mathrm{x}}$ by MOCVD. ${ }^{4,5}$ In one of those reports [5], no mention was made of the electrical quality or the impurity level of the materials. Although there have been several reports by others of the growth of AlSb by MOCVD, ${ }^{5-9}$ again very little mention has been made regarding the purity of the materials. It is well known that $\mathrm{Al}$ containing materials prepared using MOCVD tend to have larger concentrations of both $\mathrm{O}$ and $\mathrm{C}$ impurities when compared to the $\mathrm{Ga}$ containing analogue.$^{10,11}$ The presence of these impurities in $\mathrm{Al}$ containing semiconductors is due to the strength of the bond between $\mathrm{Al}$ and $\mathrm{O}$ or $\mathrm{C}$ when compared to the bond strength of $\mathrm{Al}$ to $\mathrm{P}$, $\mathrm{As}$, or $\mathrm{Sb}^{10,11}$ In this work we have taken an analogous approach to that used for improving the carbon concentration in AlGaAs where trimethylamine alane (TMAA) and triethylgallium (TEGa) were used to prepare high purity AlGaAs by using TMAA or ethyldimethylamine alane (EDMAA) and triethylantimony (TESb) to prepare AlSb by MOCVD. ${ }^{12,13}$ Herein we describe the preparation of thin films of $n$ - and p-type AlSb and $\mathrm{AlAs}_{\mathrm{x}} \mathrm{Sb}_{1-\mathrm{x}}$ grown on GaAs and InAs substrates as well as the growth of InAsSb/InAs multiple quantum well active regions on top of these cladding layers. 


\section{EXPERIMENTAL}

This work was carried out in a previously described MOCVD system. ${ }^{14}$ TMAA, TESb and $100 \%$ arsine were the sources for $\mathrm{Al}, \mathrm{Sb}$ and $\mathrm{As}$ respectively. TEGa was used to grow a $1000 \AA$ to $2500 \AA \mathrm{GaSb}$ cap on all samples to keep the $A 1 \mathrm{As}_{\mathrm{x}} \mathrm{Sb}_{1-\mathrm{x}}$ layer from oxidizing. Hydrogen was used as the carrier gas at a total flow of 9 slpm. P-type doping was accomplished using $200 \mathrm{sccm}$ to $500 \mathrm{sccm}$ of diethylzinc (DEZn) diluted to $400 \mathrm{ppm}$ in hydrogen. $\mathrm{N}$-type doping was accomplished using tetraethyltin (TESn) held at $18^{\circ} \mathrm{C}$ to $20^{\circ} \mathrm{C}$. The hydrogen flow through the TESn source was typically $20 \mathrm{sccm}$ which was diluted with $350 \mathrm{sccm}$ of hydrogen. Five to $20 \mathrm{sccm}$ of this mixture was introduced into the growth chamber. Semi-insulating epi-ready GaAs and n-type InAs substrates were used for each growth.

AlSb samples $1-2 \mu \mathrm{m}$ thick were grown at $500^{\circ} \mathrm{C}$ at either 76 torr or 200 torr with V/III ratios between 4 to 16 . The best morphology was achieved at V/III $=15$ and was independent of reactor pressure. The surface morphology of each layer was characterized by optical microscopy using Normarski interference contrast. Under this growth condition, the growth rate was $0.4-0.5 \mu \mathrm{m} / \mathrm{hr}$ for a group III transport rate of $1 \times 10^{-5}$ moles of TMAA per minute.

$\mathrm{AlAs}_{0.16} \mathrm{Sb}_{0.84}$ layers $0.5-1 \mu \mathrm{m}$ thick and lattice-matched to InAs were grown at 500 or $600^{\circ} \mathrm{C}$ and 76 or 200 torr using a V/III $=3$ to 8 and $[\mathrm{As}] /([\mathrm{As}]+[\mathrm{Sb}])=0.1$ to 0.64 in the gas phase. The best morphology was achieved when grown on a previously grown buffer layer of InAs. The growth rate ranged between $0.35-2.0 \mu \mathrm{m} / \mathrm{hr}$ for 120 minute growth times. The optimum V/III ratio is lower for AlAsSb grown at $600^{\circ} \mathrm{C}$ than AlSb grown at $500^{\circ} \mathrm{C}$ due to the more complete decomposition of TESb at the higher growth temperature.

Secondary ion mass spectroscopy (SIMS) was used to determine $\mathrm{C}$ and $\mathrm{O}$ impurity levels and dopant concentrations. The SIMS experiments were performed by Charles Evans and Associates, East, using $\mathrm{Cs}^{+}$ion bombardment. Five crystal x-ray diffraction (FCXRD) using (004) reflection was used to determine alloy composition. Layer thickness was determined using a groove technique and was cross checked by cross sectional SEM. These techniques usually agreed within a few percent.

Room temperature Hall measurements using the Van der Pauw technique were used to determine the majority carrier type and concentration of $\mathrm{AlAs}_{\mathrm{x}} \mathrm{Sb}_{1-\mathrm{x}}$ layers grown on semiinsulating GaAs. Contacts were formed by alloying $\mathrm{In} / \mathrm{Sn}(90: 10)$ or $\mathrm{In} / \mathrm{Zn}(95: 5)$ at $300^{\circ} \mathrm{C}$ to $340^{\circ} \mathrm{C}$ in a $\mathrm{Ar} / \mathrm{H}_{2}$ atmosphere.

Capacitance-voltage (C-V) and current-voltage (I-V) measurements using metal Schottky barrier diodes were used to determine the carrier type and concentration of the layers. $\mathrm{C}-\mathrm{V}$ diodes (10 and 40 mils in diameter) were formed by depositing $700 \AA$ to $1000 \AA$ of platinum by e-beam evaporation through a shadow mask. $\mathrm{C}-\mathrm{V}$ and $\mathrm{I}-\mathrm{V}$ measurements were made using two diodes in series on the epitaxial surface for samples grown on both GaAs and InAs substrates. $\mathrm{C}-\mathrm{V}$ and $\mathrm{I}-\mathrm{V}$ measurements were also made on samples grown on InAs substrates using only a single metal diode on the epi-surface and an ohmic back contact. No difference in carrier concentration was observed between the measurement configurations. Electrochemical C-V measurements were made using $0.2 \mathrm{M} \mathrm{NaOH} / 0.1 \mathrm{M}$ EDTA electrolyte under various measurement conditions using a Bio-Rad Polaron system.

\section{RESULTS AND DISCUSSION}

Previous attempts by others at doping MOCVD grown $\mathrm{AlSb}, \mathrm{AlAs}_{\mathrm{x}} \mathrm{Sb}_{1-\mathrm{x}}$ alloys n-type have failed and this prohibits their use in bipolar devices. ${ }^{6-8}$ The use of the conventional precursors trimethylaluminum (TMAl) and trimethylantimony (TMSb) or triethylantimony 
Table I. SIMS and Hall measurements of AlSb and $\mathrm{AlAs}_{\mathrm{x}} \mathrm{Sb}_{1-\mathrm{x}}$ grown on GaAs.

\begin{tabular}{|c|c|c|c|c|c|c|}
\hline \multirow[b]{2}{*}{ Sample } & \multirow[b]{2}{*}{ Material } & \multirow{2}{*}{$\begin{array}{c}\text { Growth } \\
\text { Conditions } \\
\left({ }^{\circ} \mathrm{C} / \text { torr }\right)\end{array}$} & \multicolumn{3}{|c|}{ SIMS } & Hall \\
\hline & & & $\begin{array}{c}\text { Oxygen } \\
\left(10^{17} \mathrm{~cm}^{-3}\right)\end{array}$ & $\begin{array}{c}\text { Carbon } \\
\left(10^{17} \mathrm{~cm}^{-3}\right)\end{array}$ & $\begin{array}{c}\text { Dopant } \\
\left(10^{17} \mathrm{~cm}^{-3}\right)\end{array}$ & $\begin{array}{l}\text { Carriers } \\
\left(10^{17} \mathrm{~cm}^{-3}\right)\end{array}$ \\
\hline $\begin{array}{l}2049 \\
2050\end{array}$ & $\begin{array}{l}\text { AISb- N.I.D. } \\
\text { AISb- N.I.D. }\end{array}$ & $\begin{array}{l}500 / 200 \\
500 / 200\end{array}$ & $\begin{array}{l}50 \\
60\end{array}$ & $\begin{array}{l}10 \\
20\end{array}$ & $\cdots \cdots$ & $\cdots \cdots$ \\
\hline 2100 & $\begin{array}{l}\text { AlAsSb- } \\
\text { N.I.D. }\end{array}$ & $600 / 76$ & 100 & 7 & & $p, 0.94$ \\
\hline 2103 & AlAsSb-Sn ${ }^{b}$ & $600 / 76$ & 50 & 2 & Sn, 100 & $n, 23$ \\
\hline 2107 & AlAsSb-Znc & $600 / 76$ & 80 & 50 & $\mathrm{Zn}, 7$ & $p, 14$ \\
\hline
\end{tabular}

a N.I.D. : not intentionally doped.

b N-dopant: TESn @ 20C and 646 torr.

c P-dopant: 400 ppm DEZn in hydrogen.

(TESb) has resulted in material with $\mathrm{C}$ and $\mathrm{O}$ concentrations exceeding $1 \times 10^{19} \mathrm{~cm}^{-3}$. 9 The surface morphologies were reported as very rough. ${ }^{6-8}$ We have used TMAA or EDMAA and TESb to prepare AlSb and AlAs $S_{x} b_{1-x}$ with $C$ and $O$ concentrations below $1 \times 10^{19} \mathrm{~cm}^{-3}$ (see Table I) and we have successfully doped them n-type using TESn.

SIMS and Hall measurements of undoped, $\mathrm{Zn}$, or $\mathrm{Sn}$ doped $\mathrm{AlAs}_{\mathrm{x}} \mathrm{Sb}_{1-\mathrm{x}}$ layers grown on GaAs are also reported in Table I. Both $\mathrm{C}$ and $\mathrm{O}$ levels in the undoped samples are significantly lower than previously reported results and sufficiently low to expect successful ntype doping. The physical concentrations reported were determined from reference standards where known doses of $\mathrm{C}, \mathrm{O}, \mathrm{Sn}$ or $\mathrm{Zn}$ were implanted into $\mathrm{GaSb}$ substrates. Oxygen levels measured in $\mathrm{AlAs}_{\mathrm{x}} \mathrm{Sb}_{1-\mathrm{x}}$ layers are nominally the same regardless of doping or the addition of As. At this point in time it is unclear what the source of the oxygen is in these materials. The oxygen could be coming from contaminants in the source bubblers, background in the reactor or SIMS chamber, or from reaction of the samples with air. The carbon level in undoped and $\mathrm{Sn}$ doped $\mathrm{AlAs}_{0.16} \mathrm{Sb}_{0.84}$ is significantly lower than that found in AlSb. This carbon reduction is consistent with the well known effect of increased $\mathrm{AsH}_{3}$ effectively reducing the incorporation of $\mathrm{C}$ in $\mathrm{AlGaAs}$ films. ${ }^{10,11}$ The higher level of carbon found in the $\mathrm{Zn}$ doped $\mathrm{AlAs}_{0.16} \mathrm{Sb}_{0.84}$ is most likely related to the DEZn used for doping. It is suspected that the additional carbon is largely responsible for the Hall hole concentration considering the relatively low level of zinc measured by SIMS.

The concentration of $\mathrm{Sn}\left(1 \times 10^{19} \mathrm{~cm}^{-3}\right)$ measured in $\mathrm{AlAs}_{0.16} \mathrm{Sb}_{0.84}$ by SIMS is significantly higher than the carbon and oxygen levels. Hall measurements of sample 2103 showed n-type material with an electron concentration consistent with the $\mathrm{Sn}$ concentration measured by SIMS $\left(2.3 \times 10^{18} \mathrm{~cm}^{-3}\right)$. Measurements of undoped $\mathrm{AlAs}_{0.16} \mathrm{Sb}_{0.84}$ gave hole concentrations of $2-9 \times 10^{16} \mathrm{~cm}^{-3}$. Hall measurements of $\mathrm{Sn}$-doped $\mathrm{AlAs}_{0.16} \mathrm{Sb}_{0.84}$ grown on $\mathrm{GaAs}$ showed n-type material with an electron concentration consistent with dopant flow (Table I). The electron concentration was repeatable for the same dopant flow as for samples 2103 and 2109 . However the electron concentration was not repeated in sample 2131 which was grown under the same reactant flows. The difference in doping between 2131 and the previous two runs is believed to be due a change in temperature of the TESb water bath. This suggests that $\mathrm{Sn}$ incorporation is dependent on the V/III ratio. When the dopant flow was reduced by half in sample 2132 the electron concentration fell proportionally. The Hall mobility ranged from $100 \mathrm{~cm}^{2} / \mathrm{Ns}$ to $300 \mathrm{~cm}^{2} / \mathrm{Vs}$ for these samples. 
Table II. Hall and C-V measurements of $\mathrm{AlAs}_{\mathrm{x}} \mathrm{Sb}_{1-\mathrm{x}}$ grown at $600^{\circ} \mathrm{C}$ and 76 torr on GaAs.

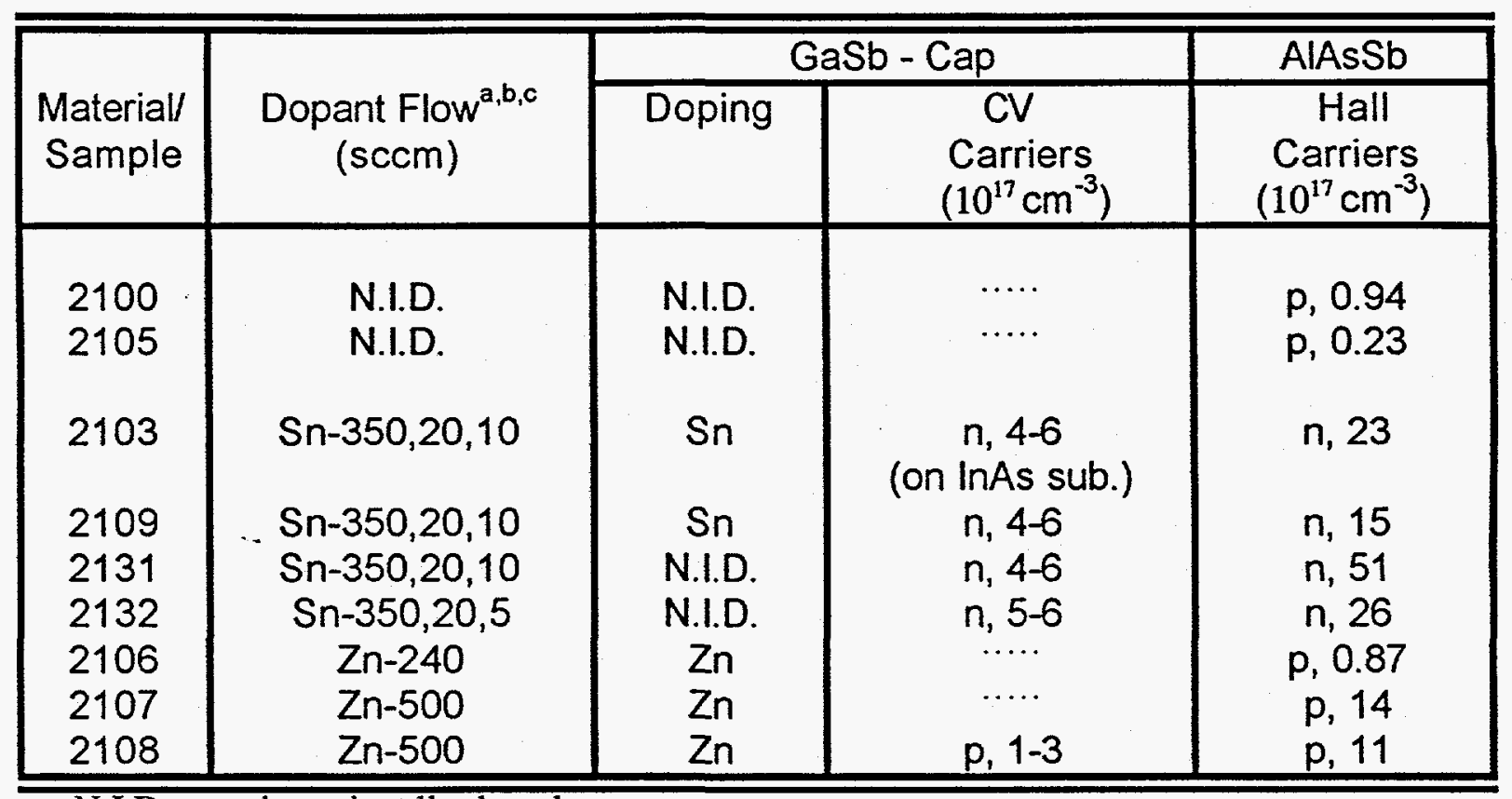

a N.I.D. : not intentionally doped.

b N-dopant: TESn @ 20C and 646 torr, H2 dilution / H2 through TESn bubbler / Mixture into chamber.

c P-dopant: $400 \mathrm{ppm}$ DEZn in hydrogen

Since all of these samples were prepared with a $\mathrm{GaSb}$ cap layer it is important to eliminate the possibility that the cap layer is dominating the Hall measurements. Hall measurements of $\mathrm{n}-\mathrm{AlAs}_{0.16} \mathrm{Sb}_{0.84}$ do not appear to be influenced by the presence of the $\mathrm{GaSb}$ cap layer. Changing the GaSb cap thickness from 1000 to $2000 \AA$ did not effect the electron concentration measured by Hall. Also, C-V measurements indicate the electron concentration of the cap layer to be $4-6 \times 10^{17} \mathrm{~cm}^{-3}$ which is significantly less than the Hall results. C-V measurements (Table II) showed no difference in electron concentrations whether the GaSb cap was intentionally doped ( 2103 and 2109) or not (2131 and 2132). This is likely due to the thinness of the GaSb cap which causes depletion of most carriers in the GaSb. Finally, I-V measurements of $\mathrm{Pt}$ diodes deposited on sample 2109 with the $\mathrm{GaSb}$ cap removed by wet etching clearly showed n-type characteristics further indicating n-type doping of $\mathrm{AlAs}_{0.16} \mathrm{Sb}_{0.84}$ grown on $\mathrm{GaAs}$.

For the growth of Sn-doped n-type AlSb, Polaron and C-V measurements using metal diodes showed good agreement for AlSb (Table III). Both measurements showed n-type AlSb (grown on InAs) with a carrier concentration of $3-7 \times 10^{17} \mathrm{~cm}^{-3}$. C-V measurements of the AlSb layer were made by removing the GaSb cap by wet etching prior to metallization. Hall measurements could not be made on any AlSb samples due to poor reproducibility in forming ohmic, metal contacts.

P-type doping of $\mathrm{AlAs}_{0.16} \mathrm{Sb}_{0.84}$ was easily achieved using $\mathrm{DEZn}$. The hole concentration measured by Hall was reproducible with dopant flow (Table II). C-V measurements again show the hole concentration of the GaSb cap to be much less than the Hall measurement indicating that the GaSb cap is not significantly effecting the Hall measurement.

We have grown a previously described pseudomorphic multiple quantum well (MQW) structure which consists of $500 \AA$ InAs barriers and $100 \AA$ InAsSb wells on the top of the above described AlAsSb cladding layers. ${ }^{15}$. The cladding layer is closely lattice-matched to the 
Table III. Polaron and C-V measurements of AlSb grown at $500^{\circ} \mathrm{C}$ and 76 torr on InAs.

\begin{tabular}{|c|c|c|c|}
\hline \hline \multirow{2}{*}{$\begin{array}{c}\text { Sample } \\
\text { Number }\end{array}$} & $\begin{array}{c}\text { Dopant Flow } \\
(\mathrm{sccm})\end{array}$ & $\begin{array}{c}\text { CV } \\
\text { Carriers } \\
\left(10^{17} \mathrm{~cm}^{-3}\right)\end{array}$ & $\begin{array}{c}\text { Polaron } \\
\text { Carriers } \\
\left(10^{17} \mathrm{~cm}^{-3}\right)\end{array}$ \\
\cline { 3 - 4 } 2126 & $\begin{array}{c}\text { Sn-300,20,10 } \\
\text { Sn-300,20,20 }\end{array}$ & $\mathrm{n}, 4-7$ & $\begin{array}{c}\mathrm{p}, 2-5 \\
\mathrm{n}, 4\end{array}$ \\
\hline
\end{tabular}

a N-dopant: TESn @ 20C and 646 torr, $\mathrm{H}_{2}$ dilution $/ \mathrm{H}_{2}$ through TESn bubbler / Mixture into the chamber.

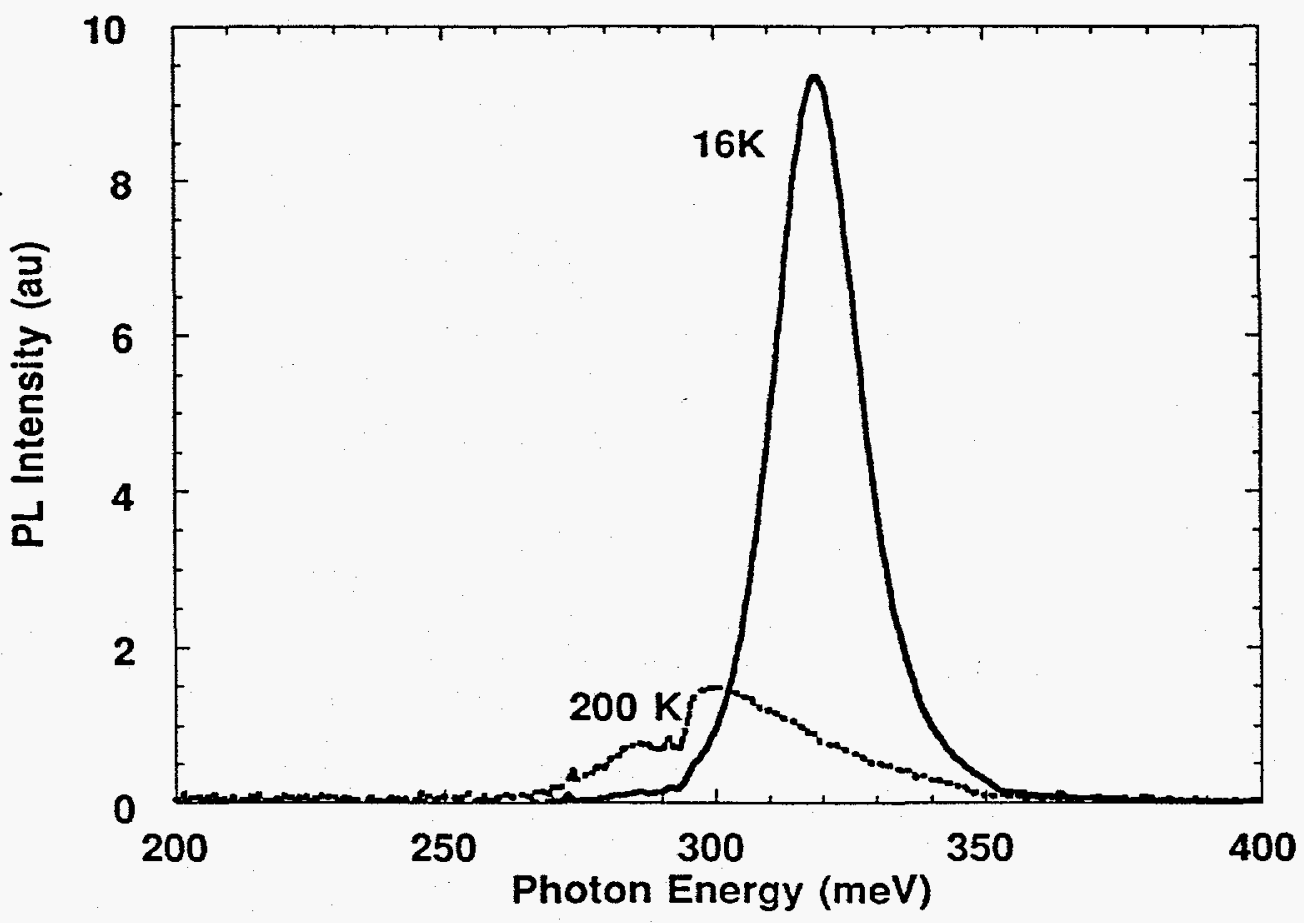

Figure 1. The photoluminescence spectra at 16 and $200 \mathrm{~K}$ of an InAsSb/InAs MQW grown on top of an $\mathrm{AlAsSb}$ cladding layer.

substrate $(\Delta \mathrm{a} / \mathrm{a}=0.001)$, and the entire active region is pseudomorphic with the substrate and cladding layers. The highly crystalline quality of the MQW active region is confirmed by FCXRD where 7 orders of satellites are observed and in optical characterization where the photoluminescence linewidth was $12 \mathrm{meV}$ at $16 \mathrm{~K}$. The photoluminescence spectra at 14 and $200 \mathrm{~K}$ of the MQW are shown in Figure 1 and are similar to the previously reported spectra of the MQW structure used in an injected laser with InPSb cladding layers. ${ }^{1}$ Photoluminescence 
output from these structures is observed at $300 \mathrm{~K}$ and it is of a similar width as that observed for $200 \mathrm{~K}$ with a slightly reduced intensity.

In summary, we have demonstrated the growth of low carbon AlSb and $\mathrm{AlAs}_{0.16} \mathrm{Sb}_{0.84}$ using TMAA or EDMAA, TESb, and $\mathrm{AsH}_{3}$ by MOCVD. The quality of this material is further evidenced by the demonstration of the first n-type doping of $\mathrm{AlSb}$ and $\mathrm{AlAs}_{0.616} \mathrm{Sb}_{0.84}$ using TESn. Hall measurements show electron concentrations in the low to mid $10^{18} \mathrm{~cm}^{-3}$ for $\mathrm{Sn}$ doped $\mathrm{AlAs}_{0.16} \mathrm{Sb}_{0.84}$. Polaron, C-V with metal diodes, and I-V measurements all confirm the n-type measurements by Hall. Polaron and C-V measurements showed Sn-doped AlSb to have an electron concentration of $3-7 \times 10^{17} \mathrm{~cm}^{-3}$. We have grown an InAsSb/InAs MQW active region on top of this AlAsSb layer and observed high quality photoluminescence from it at temperatures up to $300 \mathrm{~K}$. With this demonstration of the growth of n-type AlSb and AlAsSb and high quality active regions by MOCVD, midwave infrared lasers $(3-6 \mu \mathrm{m})$ using these materials will be prepared by MOCVD in the near future.

\section{ACKNOWLEDGMENTS}

This work was supported by the US DOE under Contract No. DE-AC04-94AL85000.

\section{REFERENCES}

[1] S. R. Kurtz, R. M. Biefeld, L. R. Dawson, K. C. Baucom, and A. J. Howard, Appl. Phys. Lett. 64, 812 (1994).

[2] H. K. Choi, G. W. Turner, and Z. L. Liau, Appl. Phys. Lett. 65, 2251 (1994).

[3] Y-H. Zhang, Appl. Phys. Lett. 66, 118 (1995).

[4] R. M. Biefeld, A. A. Allerman, and M. W. Pelczynski, Appl. Phys. Lett. 68, 932 (1996).

[5] W. K. Chen, J. Ou, and W-I. Lee, Jpn, J. Appl. Phys. 33, L402 (1994).

[6] D. S. Cao, Z. M. Fang, and G. B. Stringfellow, J. Crystal Growth, 113, 441 (1991).

[7] G. J. Bougnot, A. F. Foucaran, M. Marjan, D. Etienne, J. Bougnot, F. M. H. Delannoy, and F. M. Roumanille, J. Crystal Growth, 77; 400 (1987).

[8] M. Leroux, A. Tromson-Carli, P. Gibart, C. Verie, C. Bernard, and M. C. Schouler, , J. Crystal Growth, 48, 367 (1980).

[9] C. A. Wang, M. C. Finn, S. Salim, K. F. Jensen, and A. C. Jones, Appl. Phys. Lett. 67, 1384 (1995).

[10] G. B. Stringfellow "Organometallic Vapor Phase Epitaxy:Theory and Practice" (Academic Press, Inc., San Diego, CA, 1989).

[11] M. A. Tischler, R. M. Potemski, T. F. Kuech, F. Cardone, M. S. Goorsky, and G. Scilla, J. Crystal Growth, 107, 268 (1991).

[12] W. S. Hobson, T. D. Harris, C. R. Abernathy, and S. J. Pearton, Appl. Phys. Lett., 58, 77 (1991).

[13] R. P. Schneider, R. P. Bryan, E. D. Jones, R. M. Biefeld, and G. R. Olbright, J. Crystal Growth, 123, 487 (1992).

[14] R.M. Biefeld, C.R. Hills and S.R. Lee, J. Crystal Growth, 21, 515 (1988).

[15] S. R. Kurtz and R. M. Biefeld, Appl. Phys. Lett. 66, 364 (1995).

\section{DISCLAIMER}

This report was prepared as an account of work sponsored by an agency of the United States Government. Neither the United States Government nor any agency thereof, nor any of their employees, makes any warranty, express or implied, or assumes any legal liability or responsibility for the accuracy, completeness, or usefulness of any information, apparatus, product, or process disclosed, or represents that its use would not infringe privately owned rights. Reference herein to any specific commercial product, process, or service by trade name, trademark, manufacturer, or otherwise does not necessarily constitute or imply its endorsement, recommendation, or favoring by the United States Government or any agency thereof. The views and opinions of authors expressed herein do not necessarily state or reflect those of the United States Government or any agency thereof. 


\section{DISCLAMMER}

Portions of this document may be illegible in electronic image products. Images are produced from the best available original document. 